\title{
Wireless Data logging and Supervisory Control of Process Using Lab view
}

\author{
K.Deepthi ${ }^{1}$, Dr.A.M.Prasad ${ }^{2}$ \\ Department of Electronics and Communications Engineering \\ UniversityCollege of Engineering Kakinada, India
}

\begin{abstract}
:wireless data acquisition, data logging and supervisory control are the basic building blocks of plant automation. In this paper plant consisting of multiple boilers where multiple process variables of the boilers need to be acquired from the field is considered and analysed. The data of the process variables needs to be logged in a database for further analysis and supervisory control. A Lab VIEW based wireless data logging and supervisory control program simulates the process and the generated data are logged in to the database with proper indication about the status of the process variable. This gives the overview of modern day data acquisition system, data loggers and supervisory control techniques. Wireless data acquisition and data logging program is used to log the measurements of different process variable data in a database. The database also shows the status of the process variable as normal or abnormal.
\end{abstract}

Key words:Data acquisition,Data logging, , Lab view, Supervisorycontrol,Zigbee.

\section{Introduction}

Acquiring the multiple data, the data may be analog or discrete in nature from the field or process at high speed using multi-channel data acquisition system, processing the data with the help of a data processing algorithm and a computing device and displaying the data for the user is the elementary need of any industrial automation system. Modern day process Plants, construction sites, agricultural industry, petroleum, power distribution network, wireless sensor network, refinery industry and every other industry where data is of prime importance use wireless data acquisition, data processing and data logging equipment's. Acquiring data from the field with the help of different sensor is always challenging. Different kinds of noises are super imposed in the data. Data comes from the field with the help of transducers and data acquisition system. After acquiring data from the Field, the signal conditioning and processing operations are performed. In signal conditioning operation, different noises which are super imposed in the original process signal is removed and the signal is amplified. After the signal conditioning operation, signal is given to a signal processing algorithm which processes the signal and stores the data in a memory unit.

This paper also gives an overview of modem day data acquisition system, data loggers and supervisory control techniques. In the case study a Lab VIEW based data acquisition and data logging program is used to log the measurements of different process variable data in a database. The database also showsthe status of the process variable as normal and not normal.

LABVIEW is a graphical programming environment used by many of engineers and scientists to develop sophisticated measurement, test, and control systems using intuitive graphical icons and wires that resemble a flowchart. It offers unrivalled integration with thousands of hardware devices and provides hundreds of built-in libraries for advanced analysis and data visualization-all for creating virtual instrumentation. Lab VIEW programs are called virtual instruments, or VIs, because their appearance and operation imitate physical instruments, such as oscilloscopes and multi meters. Lab VIEW contains a comprehensive set of tools for acquiring, analysing, displaying, and storing data, as well as tools to help the troubleshoot code to write. In Lab VIEW, build a user interface, or front panel, with controls and indicators. Controls are knobs, push buttons, dials, and other input mechanisms. Indicators are graphs, LEDs, and other output displays. After build the user interface, to add code using VIs and structures to control the front panel objects. The block diagram contains this code. It can use Lab VIEW to communicate with hardware such as data acquisition, vision, and motion control devices, as well as GPIB, PXI, VXI, RS232, and RS485 instruments. Virtual Instrumentation is the combination of the user defined software and modular hardware that implements the custom systems ("Virtual Instruments") with components acquisition processing/analysis and presentation. This is user defined and focused on the needs of the application. For instance, researchers can build custom virtual instruments that can apply real-time mathematics for processing, analysis, and control involving online (live) and/or offline (from file/database) signal I/O. One key element behind the success of the virtual instruments approach is Lab VIEW, a software development tool originally developed to support the requirements of Virtual Instrumentation. 


\section{Data Acquisition}

Most measurements begin with a transducer, a devicethat converts a measurable physical quantity, such as temperature, strain, or acceleration, to an equivalent electrical signal. Transducers are available for a wide range of measurements, and come in a variety of shapes, sizes, and specifications. Signal conditioning can include amplification, filtering, differential applications, isolation, simultaneous sample and hold (SS\&H), current-to-voltage conversion, voltage-to-frequency conversion, linearization and more.

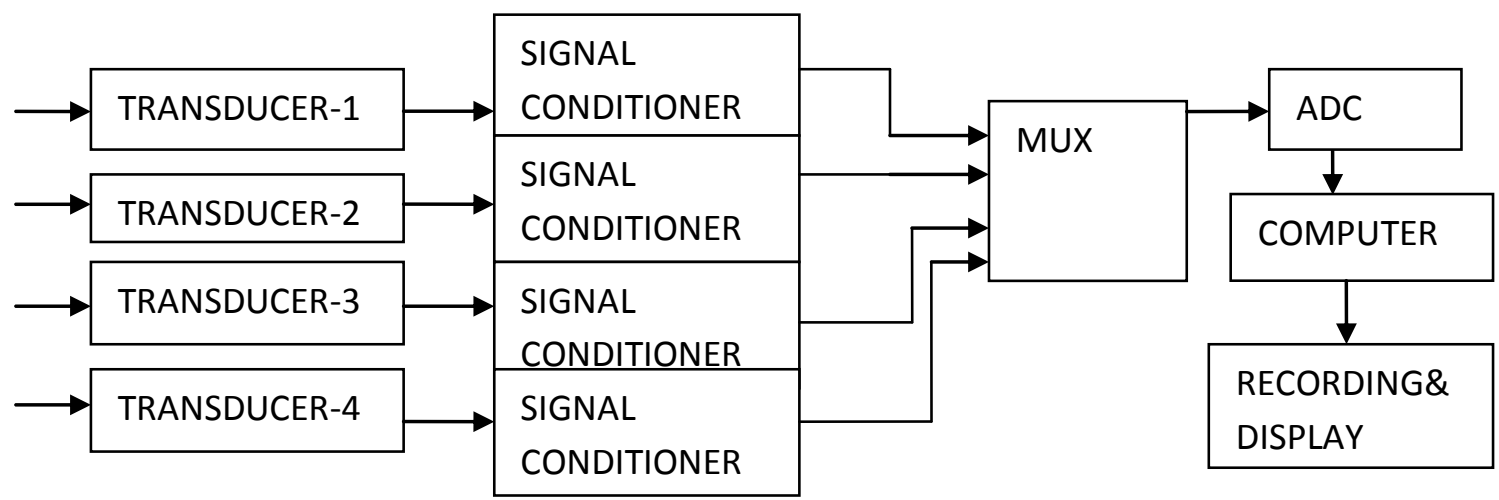

Figure1:Schematic for Data Acquisition

\subsection{Data logging And Supervisory control:}

Data logging and recording is a very common measurement application. In its most basic form,data logging is the measurement and recording of physical or electrical parameters over a period of time. The data can be temperature, strain, displacement, flow, pressure, voltage, current, resistance, power, or any of a wide range of other parameters. Real-world data logging applications such as those required in Condition-Based Maintenance, are typically more involved than just acquiring and recording signals, and require some combination of online analysis, offline analysis, display,report generation, and data sharing. Moreover, many data logging applications are beginning to require the acquisition and storage of different types of data like analog, discrete etc.

Supervisory control and data acquisition systems (SCADA) are high-level control schemes that have a long history in managing large and/or heterogeneous systems, such as electrical network grids, nuclear power plants, etc. In general, the supervisor implements a decision-making scheme based on the condition of the system.

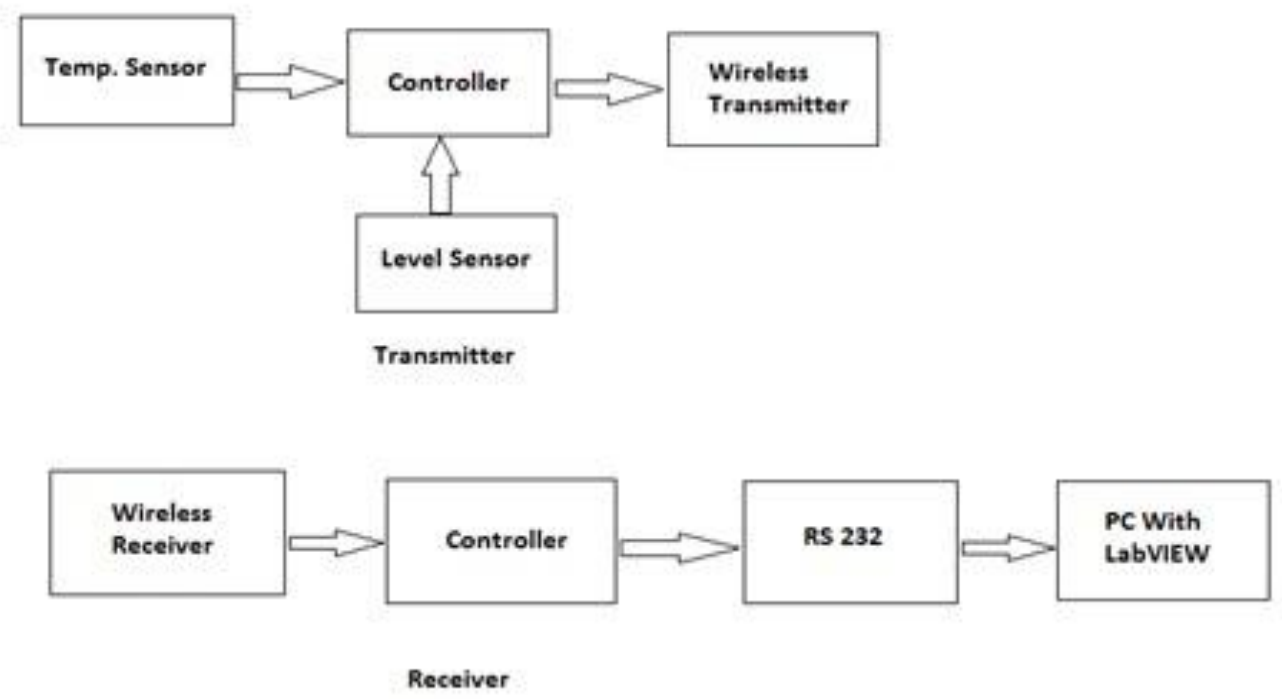

Figure2: Block diagram of wireless data logging and supervisory control

2.2. Microcontroller: It is the brain of the hard ware requirement. It executes all the necessary controlling programs by taking the input from the MAX 232. Microcontrollers are designed to perform specific tasks. Specific means applications where the relationship of input and output is defined. Depending on the input, some processing needs to be done and output is delivered. In this paper we are using ATMEGA40 pin. 
2.3. Ultrasonic sensors: Ultrasonic sensors generate high frequency sound waves and evaluate the echo which is received back by the sensor. Ultrasonic sensors are devices that use electrical-mechanical energy transformation, the mechanical energy being in the form of ultrasonic waves, to measure distance from the sensor to the target object. Ultrasonic waves are longitudinal mechanical waves which travel as a succession of compressions and rarefactions along the direction of wave propagation through the medium. Any sound wave above the human auditory range of $20,000 \mathrm{~Hz}$ is called ultrasound. Further applications of ultrasonic sensors are humidifiers, sonar, medical ultrasonography, burglar alarms.

2.4. Lm35: It is a precision IC temperature sensor with its output proportional to the temperature $\left(\right.$ in $\left.{ }^{\circ} \mathrm{C}\right)$. The sensor circuitry is sealed and therefore it is not subjected to oxidation and other processes. With LM35, temperature can be measured more accurately than with a thermistor. It also possess low self-heating and does not cause more than $0.1^{\circ} \mathrm{C}$ temperature rise in still air.

The operating temperature range is from $-55^{\circ} \mathrm{C}$ to $150^{\circ} \mathrm{C}$. The output voltage varies by $10 \mathrm{mV}$ in response to every ${ }^{\circ} \mathrm{C}$ rise/fall in ambient temperature, i.e., its scale factor is $0.01 \mathrm{~V} /{ }^{\circ} \mathrm{C}$.

2.5. RS-232 port:It isa 9 pin dual converters which is used to read or write the files. It is one of the serial port converters which reads and write the files in step manner. It is the main communicating channel between the device and micro controller.

2.6.Wireless network:Zigbee is a low power spin off of Wi-Fi. It is a specification for small, low power radios based on IEEE 802.15.4 - 2003 Wireless Personal Area Networks standard. The specification was accepted and ratified by the Zigbee alliance in December 2004. Zigbee Alliance is a group of more than 300 companies including industry majors like Philips, Mitsubishi Electric, Epson, Atmel, Texas Instruments etc. which are committed towards developing and promoting this standard. The alliance is responsible for publishing and maintaining the ZIgbee specification and has updated it time and again after making it public for the first time in 2005. The manufacturers which are members of the Alliance provide software, hardware and reference designs to anyone who wants to build applications using Zigbee.

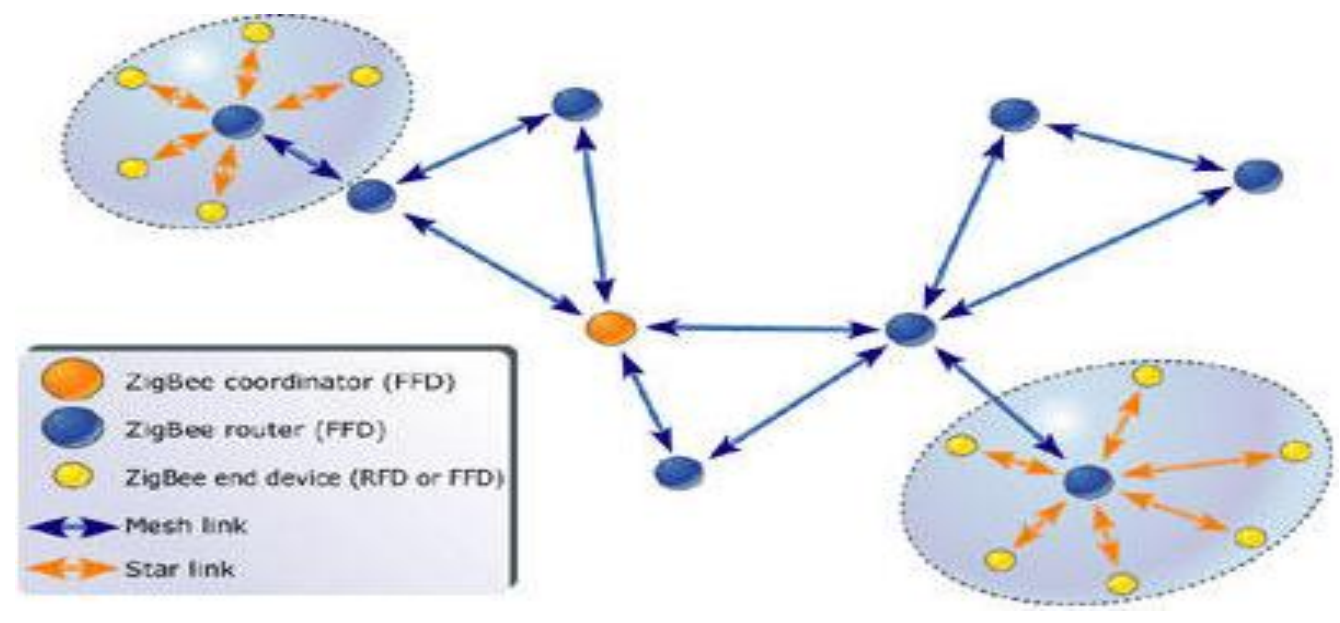

Figure 3: wireless network 

III. Figures and tables:

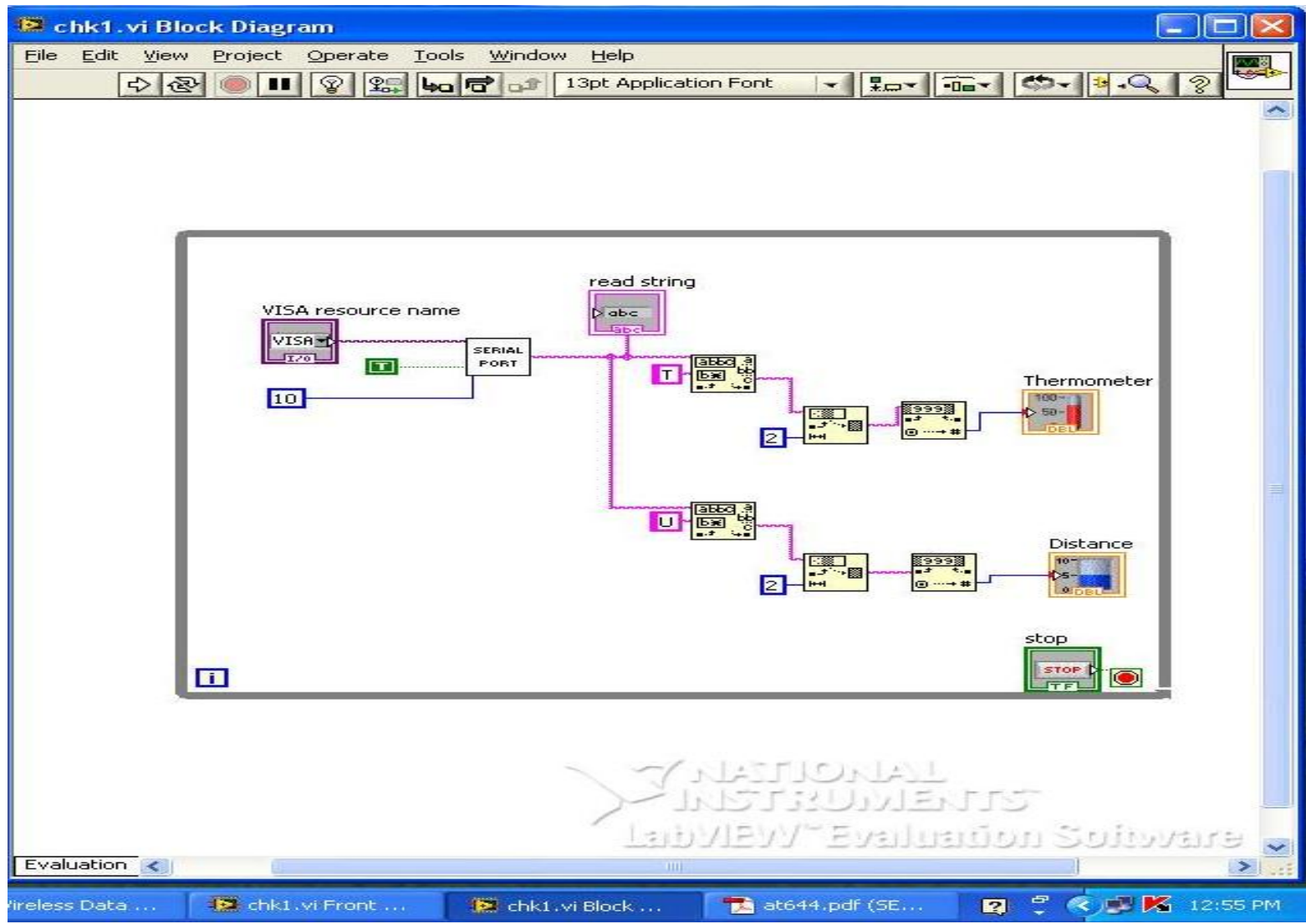

\subsection{Figure 4: Block diagram of lab view}

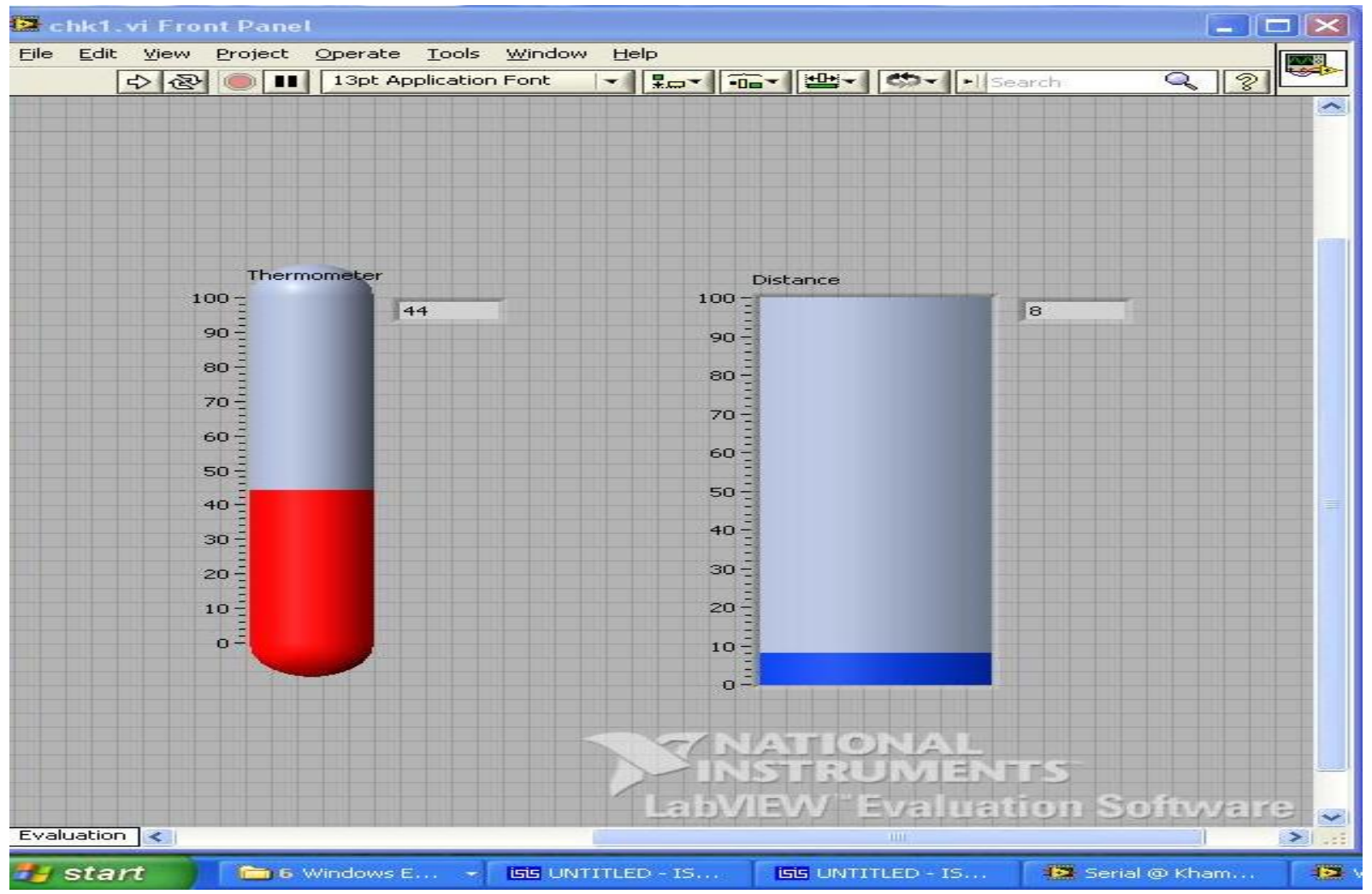




\subsection{Figure5: Front panel of labview}

The above figures 4, 5 shows the lab viewbased block diagram program and front panel of wireless data acquisition data logging and supervisory control. From figure 4 the block diagram program fordisplaying the temperature and distances of the any obstacle or furnace and from figure 5 we can saw the output of that block diagram program.

3.3.Table: Accuracy of ultrasonic obstacle avoidance:

\begin{tabular}{|l|l|l|l|l|l|l|l|l|l|}
\hline $\begin{array}{l}\text { Actual } \\
\text { distance }(\mathrm{cm})\end{array}$ & 20 & 30 & 40 & 50 & 60 & 70 & 80 & 90 & 100 \\
\hline $\begin{array}{l}\text { Distance } \\
\text { measurement }(\mathrm{cm})\end{array}$ & 20 & 31 & 40 & 51 & 62 & 69 & 82 & 96 & 102 \\
\hline Error $(\%)$ & 0 & 3.3 & 0 & 2.0 & 3.3 & 1.4 & 2.5 & 6.7 & 2.0 \\
\hline
\end{tabular}

Table 1: Accuracy of ultrasonic obstacle avoidance

\section{Simulation and results:}

The front panel of the lab view shown in the figure 4 where the temperature level is clearly indicated in thermometer and the distance is also clearly indicatedinthat. The distance will be increased temperature also increases slightly and at the same time distance decreases temperature also decreases. In the similar way we can measure the water level and temperature of any container or boilers in plants.

\section{Conclusion:}

This paper emphasizes on the data acquisition, supervisory control and data logging aspect of an industrial Process. These areas are of prime importance for computer control of an industrial process. This paper discusses Various methods of data acquisition, data logging and supervisory control and the modem development in the area. It also discusses the different control requirement and three element control scheme for boiler unit. For simulation purpose this paper used Lab VIEW which is basically used in virtual instrumentation domain. The future scope of this paper is to identify the forth coming of tsunami's, so that we can alert the government and the public. Another scope of this paper is we can get the signals from the places where human beings cannot reach to identify the water levels and temperatures.

\section{References:}

[1] LABVIEW Demos (cd's).Getting Started (National Instrumentation) 2009 edition.

[2] Joseph Luongo, "A Multichannel Digital Data Logging System, "IRE Trans" Instrum" pp, 103-106, Jun, 1958.

[3] Deichert, R,L., Burris, D,P" Luckemeyer, J" "Development of a High Speed Data Acquisition System Based on Lab VIEW and VXI, " in Prac, IEEE Autatestcan, pp, 302-307, Sep, 1997.

[4] RecayiPecen, M.D Salim, AyhanZora, "A LabVIEWBasedInstrumentation System for a Wind-Solar Hybrid Power Station, "J. Indus. Technol., vol. 20, no. 3, pp. 1-8, Jun-Aug. 2004

[5] A Hammad, A Hafez, M T Elewa, "A LabVIEW Based Experimental Platform for Ultrasonic Range Measurements, " J.DSP, vol. 6, issue 2, pp. 1-8, Feb. 2007.

[6] Aditya N. Das, Frank L. Lewis, Dan O. Popa, "Data-logging andSupervisory Control in Wireless Sensor Networks, " Int. J. Wireless Mob. Comput, pp. 1-12, 2006

[7] F, Figueroa, S, Griffin, L. Roemer and J. Schmalzel, "A Look into The Future of Data Acquisition, " IEEEInstrum, Meas, Mag" vol. 2, issue 4, pp, 23-34, Dec, 1999.

[8] Samuel Daniels, Dave Harding, Mike Collura, "Introducing Feedback Control to First Year Engineering Students Using LabVIEW, "inProc. American Society Engng.Edu, Annual Corif- Expo.,Session 2161, pp. 1-12, 2005.

[9] Ziad Salem, Ismail AI Kamal, AIaa AI Bashar, "A Novel Design of an Industrial Data Acquisition System, " in Proc. Int. Con! Iriform.Commun.. Technol., pp. 2589-2594, April 2006. 